Article

\title{
Digital Innovation in Times of Emergency: Reactions from a School of Management in Italy
}

\author{
Tommaso Agasisti , Federico Frattini and Mara Soncin * $\mathbb{D}$ \\ School of Management, Politecnico di Milano, 20156 Milan, Italy; tommaso.agasisti@polimi.it (T.A.); \\ federico.frattini@polimi.it (F.F.) \\ * Correspondence: mara.soncin@polimi.it; Tel.: +39-022-399-9523
}

Received: 17 November 2020; Accepted: 8 December 2020; Published: 10 December 2020

\begin{abstract}
The study explores how the COVID-19 outbreak prompted digital innovation in a Higher Education Institution (HEI) by providing evidence on the dimensions leveraged, the initiatives organised and the organisational results achieved. By means of an exploratory single case study based on a School of Management located in Northern Italy, the study proposes a process model to highlight how digital innovation has been fostered during the emergency. Results highlight the relevance of both technological and cultural aspects that supported the digital transformation during the crisis. The dimensions of digital readiness and cultural openness, together with a defined strategic orientation, represented relevant facilitators of the digital innovation process. In turn, digital innovation had important implications for sustainability, which was fostered by increasing the accessibility to quality education and addressed as a topic of many of the digital contents delivered. Thus, the study contributes to the stream of research that investigates how digital innovation in HEIs and other public administrations happens and how such an innovation can support sustainability. Finally, the paper provides practical implications on both technological and cultural aspects of innovation.
\end{abstract}

Keywords: digital innovation; higher education; online education; crisis management

\section{Introduction}

The COVID-19 outbreak forced the digitalisation of most of the public services worldwide, collapsing in a few weeks a process of strategic planning and deployment that would have taken years to fully realise [1]. In a world on lockdown, Higher Education Institutions (HEIs) reacted promptly by transforming almost all their activities - teaching, research, administration and the so-called "third mission" - into a digital format, totally switching to a forced digitalisation [2,3]. Online teaching and learning activities were soon labelled emergency remote teaching-as they lost the fundamental pre-stage of planning and instructional design that characterises online teaching [4]. Despite its potentiality for the democratisation of Higher Education (HE) [5], online education has rather exacerbated equity issues during the crisis, generating barriers especially for lower-income students and highlighting the extent of the digital divide [6]. This aspect has important implications for the sustainability of HEIs as providers of quality and equitable education, which is crucial in pursuing the sustainable development goal related to ensuring quality education for all [7]. The picture of emergency increased, in turn, the pressure on the faculty and the administrative staff, who adapted their activities of teaching, research and student support to a distance mode only [6].

Several layers of complexity were thus amplified during the shock caused by the COVID-19 crisis, whose characteristics of disruptiveness and massiveness prompted digital innovation in an unprecedented way [8]. From a complementary perspective, however, the recent crisis offered unprecedented opportunities to foster digital innovation by leveraging on the resiliency generated by the disruptive shock, which in turn can generate positive external effects on sustainability, by means of 
a broader digital communication on sustainability topics as well as through additional forms of open and free quality education [9].

Interpreted either as an accelerator of an ongoing process or as a radical changemaker [1], the shift of paradigm imposed by COVID-19 and undertaken by HEIs poses the issue of figuring out how they approached such a transformation. Despite many interventions being designed to be temporarily, they are likely to affect the functioning of the HE sector structurally [4]. Such a context generates a gap with previous research about the digital transformation, which mainly investigated the dimensions, the opportunities and the challenges of a strategic implementation of digitalisation, stressing a planning stage that was missing during the crisis [10-12]. The specificities of the new dynamics in HE have been recently investigated by international scholars, who mostly focused on the impact of the shift to online teaching $[4,13,14]$, despite the fact that the turnaround that invested HEIs is much broader and includes any kind of core and support activities carried out by universities. The current research addresses this gap, by taking a holistic approach to the digital innovation prompted by COVID-19 in the HE context.

To do so, the paper analyses the School of Management to which the authors are affiliated by means of an exploratory case study approach. By realising semi-structured interviews to the key actors in the organisation and by triangulating results with secondary data sources, the paper proposes a process model to understand how HEIs react to an exogenous state of emergency to develop new digital attitudes and processes and what are the internal dimensions leveraged as well as the organisational results observed. The empirical setting of the research is represented by Italy, the first western country affected by the pandemic, where the main set of fast-track procedures involved school and university closure $[15,16]$. In detail, the HEI under investigation is located in Northern Italy, one of the areas mostly hit by the pandemic and characterised by a marked resiliency. This is also one of the peculiar traits of the organisation, which reacted, initially, by adapting its activities and routines to a new way of working and, secondly, by creating new set of digital routines, making the most out of the forced digitisation. In this transformation, both technological and cultural aspects emerged as central elements to support a proactive response to the emergency.

The paper contributes to highlight the existence of a close relationship between the propensity to technological innovation and the organisational culture, by contributing to expand the realm of knowledge about the factors fostering digitalisation in public administrations, especially in response to an exogenous shock as the one caused by COVID-19. Moreover, the paper highlights how digital innovation can contribute to foster sustainability through quality education, by widening its accessibility and equity, and how it can reinforce the knowledge on sustainability matters, often addressed in the digital contents delivered by the School. In practical terms, the paper provides indications on digital innovation initiatives that can support the plan for digitalisation that HEIs must undertake from now on [1].

The remainder of the paper is organised as follows. Section 2 presents the conceptual background of the paper, while Section 3 refers to the main materials and methodology used in the study. Further, Section 4 reports the results obtained by our investigation, which are finally discussed in Section 5.

\section{Conceptual Background}

Conceptually, the paper is based on the literature about digital innovation and digital transformation, as well as on the concept of corporate entrepreneurship, defined as a strategic organisation-wide transformation in the allocation of resources to new activities, in a turnabout that reflects entrepreneurial behaviour $[17,18]$. For both concepts, we discuss the main definitions as well as the main drivers and challenges.

The concept of digital innovation, in its broader definition, can be referred "as a product, process, or business model that is perceived as new, requires some significant changes on the part of adopters, and is embodied in or enabled by IT" [19] (p. 330). Chan et al. [20] trace a roadmap to digital innovation that starts from digital technologies that, combined with organisational capabilities and 
environmental influences, may produce digital innovation and, in some cases, turn into a disruptive digital innovation. The introduction of digital innovation in public administrations has been often labelled under the term "e-government", meaning the use of ICT to deliver public services. This strand of research has attracted much attention among public sector scholars, who investigated drivers and barriers of its diffusion [21] and defined frameworks to establish the level of e-maturity in public organisations [22,23]. Among the barriers to the use of digital technologies in public administrations, West [21] identifies technical, political, organisational, legal and financial aspects. Drivers, on the other side, are widely related to external dimensions, such as a sense of vulnerability, new learning capabilities that push market boundaries or an emergent normative pressure [24,25]. Especially in the public sector, the important focus towards stakeholders has been highlighted. Indeed, digitalisation has been interpreted as a means to improve efficiency, effectiveness, simplicity, openness, transparency and accountability for citizens [26].

Recent research highlighted how the literature has been focused so far on "hard" aspects, by looking for the objective knowledge produced by digital innovation $[27,28]$. On the contrary, the transformation process ending in digital innovation involves organisational aspects entailing leadership, individual interests and values in order to affect organisational processes and culture [28]. This set of compound elements finally affects value creation for the final users and leads to an organisational transformation [29]. In this respect, digital innovation is the result of a process that requires a profound transformation, which is technological only in part. The current study builds on these aspects by looking at both the technological and the cultural elements of digital innovation.

When looking at HEIs in particular, digital innovation has been described as the introduction of digital processes, teaching methods and tools, the adoption of open science policies and the rethink of universities' role as prompters of digital innovation in a broader ecosystem [30]. By causing a shift of paradigm, these changes may produce tensions related to the new way of creating, proposing and capturing value. Increased digital skills, a customer-centric approach and diversified sources of revenues are among the solutions proposed to overcome the arising challenges [31]. The shift to digital innovation in the HE sector has largely accelerated over the last years in tandem with the larger availability of technological resources for education and research. This process has been intended as a means to improve or redesign the educational experience and the university way of working [32] but also as a forced switch to stay relevant in the sector [31]. The changing needs of learners prompted the use of digital technologies by also influencing the culture of teaching and learning [33]. The current emergency, in particular, has put at the centre the open issue of the effectiveness of digital technologies for education, fuelling the debate on the topic $[4,13]$. This, in turn, affects importantly the discourse about sustainability in $\mathrm{HE}$, as, in theory, online learning offers new possibilities in this direction, while the practical equity of quality education is still far from its full realisation $[6,9]$. The exogenous shock caused by the COVID-19 pandemic generated an unprecedented discontinuity and exacerbated previous trends, forcing a full switch to digital that triggered a new impetus for digital innovation, and this represents the specific background of our study.

A second stream of related studies is connected to the concept of corporate entrepreneurship, a process defined to be strategic transformation as the consequence of entrepreneurial orientation—thought and action—which changes the way in which resources are employed [17,18]. Corporate entrepreneurship is about "people—either individually or collectively—using innovation to exploit new opportunities and create value" [34]. The innovation circle generated may bring to the generation of new products, processes and organisational methods [35]. Stopford and Baden-Fuller [36] analysed the internal and external triggers of corporate entrepreneurship, finding some common attributes related to proactiveness, aspirations beyond current capabilities, team-orientation and learning capabilities. Among the barriers to corporate entrepreneurship, aspects like the emergence of a hostile environment are found to be relevant obstacles to the diffusion of innovation. In this respect, it is particularly important to build consensus and trust around the emerging innovation [37]. Informal cultural aspects are critical in this context and have been mentioned among the main mediators 
of the diffusion of corporate entrepreneurship [38]. Organisational culture influences the cognitive framework in which innovation is perceived, and for this reason, it is a particularly relevant aspect of investigation [39].

At the intersection between the stream of literature on digital innovation and the one on corporate entrepreneurship, scholars highlighted the relevant role of informal aspects like the organisational culture. This is critical to promote innovative actions that are increasingly technology-driven. Both the cultural and the technological dimensions are addressed in the current analysis, in addition to elements that characterise organisational innovation in times of crisis, like communication. Indeed, three main dimensions have been found to be crucial in supporting HEIs in troubled times, fostering at the same time digital innovation. These elements represent the theoretical dimensions through which our case is interpreted, namely, (i) technology, (ii) communication and (iii) organisational culture.

First, technology is the enabler of the transformative process and represents the "hard" component of the triangle. In its meaning, it ranges from the technical infrastructure, i.e., the basis on which digital innovation can flourish, to the skills to be internally owned or externally acquired to make digital innovation happen [40]. In this respect, digital innovation becomes the result of either an internal or an Open Innovation process [41]. Further, in response to a disruptive change, the organisation may develop new technological capabilities that, in turn, reinforce their agility in responding to additional digital challenges [21]. The technological dimension may be particularly disruptive in pre-digital organisations as HEIs, where the adoption of digital innovation requires to rethink profoundly the business models, processes and products [42].

Second, communication channels become crucial for guaranteeing the informative flow, the regulation compliance and the emotional support to the entire community (i.e., students, personnel, society at large) [43]. Indeed, communication is the process through which the organisation connects to another part in its interior (intraorganisational communication) or to other actors of the network (interorganisational communication) [44]. Adopting a rapid response and a clear communication have been found to be particularly beneficial in times of emergency [45]. When disruptive events happen, they generate increased density of communication, less centralised networks and increased uncertainty. Information technology, together with boundary spanners (i.e., key roles able to interconnect different parts of the organisation) are critical elements for successful communication [44]. Moreover, in a world at a distance as the one imposed by the pandemic, technology becomes the only enabler of any communication channels, thus inducing an overlap between the two components.

Finally, the organisational culture influences the success of the implementation and the adoption of a digital innovation [46]. Research has also demonstrated how the organisational culture may act as a barrier to the innovation process, by highlighting the role of routineness, formalisation and complexity in hindering innovation [47]. In this respect, the organisational culture composes the "soft" side of innovation but often the most critical. To avoid that the potential of a digital innovation remains unaccomplished, the underlying cultural values need to be fully acquired and routinised [48]. The governance of the digital innovation is relevant in this process, especially in its structural parameters as vertical mechanisms and horizontal coordination [49]. Implementing digital innovation at the organisational level, in fact, requires a turn in mindset that passes through the creation of a digital culture [50]. In this respect, analysing the role of organisational culture in influencing digital innovation is a crucial element to investigate its implementation. Based on these conceptual premises, the roles of technology, communication and organisational culture are explored in the paper as relevant dimensions influencing the process of digital innovation in HE, acting as enablers or barriers during the shift of paradigm prompted by the COVID-19 outbreak.

\section{Materials and Methods}

The paper is based on an exploratory design, in which a single case study approach [51] has been intertwined with the principles of engaged scholarship [52]. The first point is justified by the possibility to carry out a deep investigation of the transformation driven by digital innovation, in which 
dimensions of organisational complexity emerge together with contextual uncertainty caused by the global emergency, thus producing a complex and unexplored field of empirical investigation [53,54]. The second point is enabled by the affiliation of the authors to the organisation under investigation, a fact that ensured high endorsement by the involved actors as well as first-hand data and direct observation on the ground.

In detail, the organisation investigated in the study is a School of Management located in Lombardy region, the first and most hit area (after China) during the COVID-19 outbreak. The School of Management is part of a flagship technological university and offers both Bachelor of Science (BSc, nearly 750 matriculated per academic year) and Master of Science (MSc, nearly 650 matriculated) in Management Engineering, as well as MBAs and post-lauream courses by means of its international Business School. The large educational offer provides the possibility to explore the approach to digital innovation in different contexts and as such enriches the scope of the study.

As primary source of data, interviews were conducted with the leading academic and administrative roles in the School. The interviews were taken in the period July-September 2020, either in person or via web conferencing platform, due to the problematic healthcare situation. Each interview lasted between 30 and $60 \mathrm{~min}$. In total, seven key roles have been involved in the interviews. The sample is considered to be sufficiently representative given that it covers all the key roles in the governance and in the main decisional processes of the School. We used a semi-structured interview format in which open-ended questions were posed in order to facilitate the free expression of the interviewees. The main topics were related to the conceptual dimensions that guide our analysis, addressed through a narrative approach that usually followed the temporal evolution of the events and, in turn, the kind of digital innovation introduced. Given the responsibility level of the interviewees, the questions regarded how she/he approached the governance of the emergency, the role of technology in supporting the crisis, the type of communication activated, the relationship with external stakeholders like students and with the community at large, and the approach to human resource management within the School. Finally, a conclusive question about the lessons learnt and the main strengths and weaknesses of the activities organised was posed. Additional details about the roles of the informants and the main topics tackled during the interviews are presented in Table 1. The same Table reports the sources of secondary data, namely, quantitative information and statistics provided by the School about the number of people involved in digital initiatives, the type of activities and their duration. Additionally, public data were analysed by means of the screening of websites, press news and presentations.

Table 1. Data sources used in the study.

\begin{tabular}{cc}
\hline \multicolumn{2}{c}{ Primary Data Source: Semi-Structured Interview } \\
\hline Roles & Duration (minutes) \\
\hline Academic director & $56^{\prime}$ \\
Administrative director & $52^{\prime}$ \\
Chief Information Officer & $45^{\prime}$ \\
HR Director & $34^{\prime}$ \\
Communication Division Manager & $48^{\prime}$ \\
Chief Commercial Officer & $41^{\prime}$ \\
Full professor/Director of Corporate relations & $40^{\prime}$ \\
\hline \multicolumn{2}{c}{ Main Topics } \\
Organisational response \\
Communication aspects \\
Technological innovations \\
Community engagement \\
Human resource management \\
Lessons learnt \\
\hline
\end{tabular}


Table 1. Cont.

\begin{tabular}{c}
\hline Primary Data Source: Semi-Structured Interview \\
\hline Secondary Data Sources and Data Triangulation \\
\hline Secondary data provided by the Communication Division \\
Secondary data collected on the web \\
Final data triangulation with: Dean and Associate Dean \\
\hline
\end{tabular}

All the interviews were recorded and transcribed verbatim. They were conducted by one of the authors, who also carried out the first data coding. Given that the narrative of the interviews generally followed the temporal evolution of events, the primary coding was aimed at identifying recurring themes related to the main conceptual dimensions, namely communication, technology and organisational culture, while secondary coding was intended to let sub-topics emerge from the text. Finally, the recurring topics and digital innovation initiatives were clustered to compose the main results of the study. The results were triangulated by means of secondary data as well as through final meetings organised with the Dean and one of the Associate Deans of the School.

\section{Results}

The results from the study allowed to formulate a process model that highlights how digital innovation prompted by the COVID-19 pandemic has been implemented in the School of Management, as graphically represented in Figure 1. We started our analysis from the concept of organisational mission and identity, which proved to be particularly relevant in the context of HEIs, being the strategic, structural and cultural (internal) dimensions on which the organisation builds its (external) reputation [55]. As important internal dimensions, the organisational mission and identity influence the organisational set of processes and procedures, with reference to teaching, research and outreach activities. The pandemic has profoundly impacted on all the university activities, fostering (and somehow forcing) digital innovation. Our results confirmed the crucial role played by three set of enablers, theoretically introduced in Section 2, namely, communication, technology and organisational culture. These dimensions have been leveraged to produce the several forms of digital innovation described below.

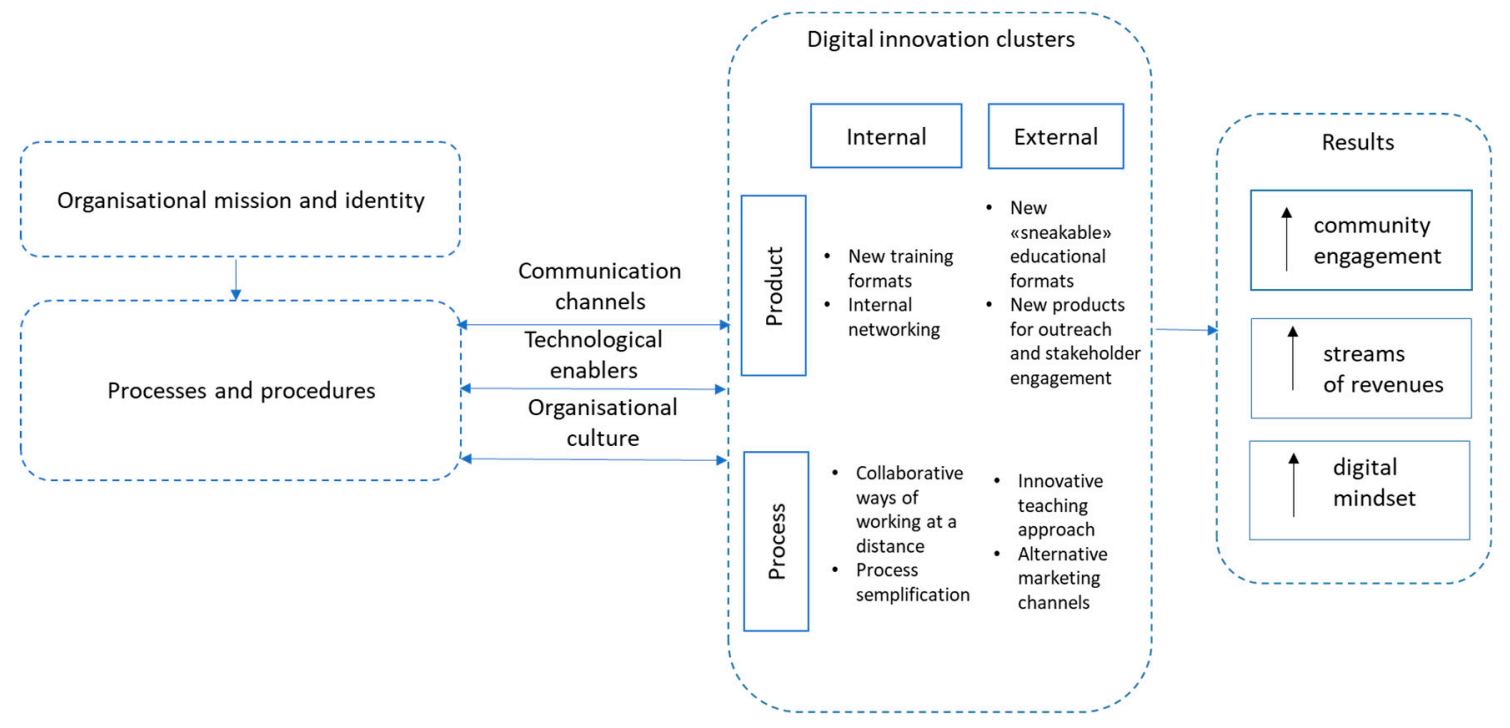

Figure 1. Digital innovation framework resulting from the study. 


\subsection{Describing Digital Innovation in the School}

Jointly fostering on the mentioned dimensions, the forms of digital innovation produced in the School have been clustered on the basis of their main features. First, they are diversified according to the typology of digital innovation introduced, distinguishing between product and process innovation. Secondly, a distinction on the basis of the kind of stakeholder to which they are addressed is presented, highlighting whether the innovation was targeted to internal (i.e., teaching and administrative staff) or external (i.e., students, prospects, alumni, companies, partners or society at large) stakeholders. At the intersection, the cases of digital innovation introduced in the School are presented, while they are more extensively described in Table 2, which also provides detailed exemplifications. It is worth to stress that this classification has emerged from our findings and is not a formal classification defined a priori. However, the clusters are strongly connected to the literature given that, on the one hand, the classification of services and activities on the basis of their end-users is widely accepted among public scholars [56]. On the other hand, the classification by product/process is based on the kind of innovation that can be generated in an organisation according to the literature on corporate entrepreneurship [17,18,35,36].

Regarding digital innovation under the form of a product for internal stakeholders, the School offered (i) brand new possibilities of training for the staff-especially for the administrative personnel—as well as (ii) brand new events for facilitating networking. The training activities were selected from external providers and gave the opportunity to train the staff on current topics, such as teleworking, stress management, balance of work and private life, for guaranteeing job sustainability and inclusivity. The training programmes were delivered in person in the past, while the emergency pushed the organisation to think about alternative ways of delivery totally online, by means of online lectures that guaranteed at the same time high personnel engagement and high quality of the knowledge acquired. As a second form of digital innovation, the necessity to keep high the sense of community fostered the creation of networking online events, whose contents somehow evolved during the crisis. Most of them were delivered by means of Microsoft Teams, which was massively used during the crisis as the main web conferencing platform. The first initiatives were meant at keeping the contact at a distance, and as such were simply in their technological design, but effective in their application and in the possible long-term effects on the organisational mindset:
At the end of February we created a chat in Teams in which we could even just say hello to all the administrative staff. We just wanted something to stay close to the staff and to be playful with them. We immediately understood it was perfectly working, as people started to share pictures, videos or just to react to other people's messages. We created an amazing legacy of that months, and we still use that tool even though we meet in presence by now. In the end, I think we acquired that digital approach as a competence, today. (Administrative Director)

These kinds of networking initiatives were also intended to share new projects, facilitate the circulation of ideas and stimulate the interaction between the governance and the staff. As an example, the "virtual coffee" was intended to replace the informal moments around the coffee machine, typically used for informal updates and conversation:

We used that moment (the virtual coffee) to keep everyone updated and connected about the latest news on our business. It was also used as an informal moment to update anyone about the general situation, and it has been highly appreciated by the staff, because usually it is not that easy to meet all the staff in a room and talk, while it became possible online. (HR Director) 
Table 2. Description of the digital innovation activities by stakeholder.

\begin{tabular}{|c|c|c|c|c|}
\hline & $\begin{array}{l}\text { Internal (Administrative Staff, } \\
\text { Teaching Staff) }\end{array}$ & Example & $\begin{array}{l}\text { External (Students, Prospect, Alumni, } \\
\text { Companies, Partners, Society) }\end{array}$ & Example \\
\hline \multirow{2}{*}{ Product } & $\begin{array}{l}\text { New online formats for training on } \\
\text { hard and soft skills by using purely } \\
\text { online platforms }\end{array}$ & $\begin{array}{l}\text { Hours of training on smart } \\
\text { working, stress management, } \\
\text { English language but also } \\
\text { vertical skills (e.g., accounting) } \\
\text { and teaching skills }\end{array}$ & $\begin{array}{l}\text { New educational formats (in addition to the complete } \\
\text { switch to online delivery) for meeting the need of } \\
\text { companies and consolidating the offer for lifelong learning }\end{array}$ & $\begin{array}{l}\text { Short online programmes made of } \\
\text { nearly } 950 \text { clips delivered at a } \\
\text { discounted price in } 2020\end{array}$ \\
\hline & $\begin{array}{l}\text { New events for consolidating } \\
\text { networking and transfer of } \\
\text { knowledge within and between } \\
\text { administrative and teaching staff }\end{array}$ & $\begin{array}{l}\text { Online events held on a regular } \\
\text { basis to foster the sense of } \\
\text { community also at a distance }\end{array}$ & $\begin{array}{l}\text { Webinars on hot topics or managerial trends by } \\
\text { interacting with CIOs, politicians, field experts }\end{array}$ & $\begin{array}{l}\text { Webpages created by stakeholder and } \\
\text { containing materials, short videos } \\
\text { and linked to webinars involving } \\
\text { nearly } 190 \text { guest speakers and } 40,000 \\
\text { people enrolled }\end{array}$ \\
\hline \multirow{2}{*}{ Process } & $\begin{array}{l}\text { Remote working enabled by digital } \\
\text { technologies that fosters a new } \\
\text { cultural approach }\end{array}$ & $\begin{array}{l}\text { Make the best of the critical } \\
\text { situation by leveraging on home } \\
\text { working to foster a new mindset } \\
\text { and digital culture }\end{array}$ & $\begin{array}{l}\text { Innovative teaching methodologies to deliver the courses } \\
\text { at all levels (bachelor, master, post-graduate) online; to } \\
\text { enable the process switch to online, formal and informal } \\
\text { sharing among the teaching staff }\end{array}$ & $\begin{array}{l}\text { Webinars held by the faculty or by } \\
\text { external guests on specific innovative } \\
\text { teaching methods to be applied } \\
\text { during the online semester (and } \\
\text { later on) }\end{array}$ \\
\hline & $\begin{array}{l}\text { Process simplification by means } \\
\text { of digitalisation }\end{array}$ & $\begin{array}{l}\text { Modification to some } \\
\text { administrative processes to } \\
\text { guarantee service continuity } \\
\text { and, at the same time, to foster } \\
\text { process simplification }\end{array}$ & $\begin{array}{l}\text { Use of alternative (and additional) marketing channels by } \\
\text { fostering the contacts and communication created by } \\
\text { means of webinars, short courses, etc. } \\
\text { Large use of CRM for profiling } \\
\text { Ah hoc communication for prospect international students } \\
\text { (e.g., informative videos on the local situation) }\end{array}$ & $\begin{array}{l}\text { Communication sent to companies in } \\
\text { which, together with the } \\
\text { communication of the free webinars, } \\
\text { additional contents were offered on } \\
\text { similar topics (at a surcharge) }\end{array}$ \\
\hline
\end{tabular}


Other kinds of informal events involved, for example, the creation of a film forum organised by the international office to develop common knowledge on foreign countries or the discussion between a member of the faculty and the administrative staff, to facilitate the connection between the two groups that are often separated in their activities. Many informants confirmed the success of this kind of initiatives that generated new connections and facilitated the emergence of personalities who were usually not inclined to intervene in joint debates:

Online we had the possibility to connect with new people more easily than in presence. Even persons that had never had something to do with each other had the hook to start a connection and discover something in common, and this now favours synergy in our everyday job. (HR Director)

In terms of product digital innovation for external stakeholders, two main outputs were generated during the emergency. First, the contingent situation pushed the organisation to rethink its education offer. Apart from totally rethinking the teaching process, the organisation built on the contingent situation to provide new "sneakable" short educational formats targeted to the business word. From the technical side, the new products leveraged on the previous experience of the School in the production of digital contents (the first digital MBA was offered by the business school in 2014), a fact that played in favour of the switch. The topics were variously related to management and with a strong connection to the current problems that companies may face:

When we got in contact with companies, we were immediately told how they had lost any possibility to plan training activities. They were rescheduling activities totally switching to smart working and had to deal with many urgencies. That is why we decided to offer short self-paced programmes that could have been accessed on our Learning Management System (LMS). This way, we came back to the corporate world with a product that was not in conflict with their organisational problems, and indeed it's been a success. (Director of Corporate Relations)

In the relationship with external stakeholders, the need to keep the engagement high, especially in times of crisis, represented an additional source of digital innovation product. As a form of social responsibility that leveraged on the organisational values and as a form of interaction and communication with the internal and external community, the School started to offer cycles of webinars on several current issues. Overall, ninety webinars were held in the period between March and July 2020 and attracted more than 40,000 enrolled people and 20,000 participants. A total number of 190 guest speakers were involved, who belonged to the corporate world, like CEOs and CIOs or were field experts or representatives of the institutions at national level. The topics discussed often included aspects related to the economic, social and environmental sustainability as important matters triggered by the current crisis. The webinars were communicated by means of direct mails and social media, by profiling the users through a CRM application. In close relation to the webinars, a total number of nine webpages were activated since March to provide useful contents to the different types of stakeholders (each webpage was specifically designed for a single stakeholder, such as companies, students, public administrations, etc.) On the technical side, the webinars were offered on Teams live events, which was a choice following the adoption of Microsoft Teams as the main web conferencing platform for meeting and for teaching during the emergency in the whole university. This experience gave the School the possibility to organise dissemination activities, keeping at the same time a direct channel of communication with the main stakeholders and gaining expertise on a new format of digital connection with the internal and external audience:

In March, we started to think about what we could do to reach out our stakeholders. We wanted to be the reference point of our community also in time of emergency, as even in a moment of crisis we could keep on learning something. [ ... ] First, this gave us the possibility to involve distinguished experts that usually do not give lectures in our classrooms. Second, we obtained an amazing response by the audience, as we got up to 4000 enrolments to a single webinar, while in our "big" events in person we do not go beyond 400. (Communication Division Manager) 
The common trait of the new digital products was that of leveraging on smart learning as a new way to approach education in a digital format and to foster sustainability through a quality, open and equitable education. It is worth to underline that the technological dimension was the enabler and not the final aim, as the idea of a digital innovation is much more comprehensive, as stated by an informant when discussing about the LMS:

Our online platform worked well, but that was not the reason why we developed new products. The fact that we had a good platform, though, allowed us to offer something that we would have not known where to offer otherwise. (CIO)

Further, other forms of digital innovation involved the organisational processes. The traditional ways of working were completely revolutionised during the crisis, impacting on both internal and external processes. On the internal side, the forced shift to remote working fostered the use of digital tools for collaboration and interaction. As mentioned, the main platform for meetings and presentations was Microsoft Teams, which was also used for all the teaching activities. The organisation had already experimented the use of teleworking for the administrative staff, despite not to this extent. Moreover, on the basis of this past experience, the switch to remote working happened smoothly and was generally perceived as a form of protection and attention to the staff. Apart from transforming the way of working by the personnel, the shift to remote working seemed to have triggered a new mindset in the staff, as highlighted by our informants:

This is the culture that we are trying to create: making people feel responsible for their objectives, understanding that a meeting is effective also at a distance. If you will give clear objectives to the personnel, each one will organise his/her activities to achieve them, online or not. This is what we could find different in the future, without noticing it. (HR Director)

The transition to remote working impacted also on the internal administrative process flow. By eliminating any forms of physical interaction, some of the processes were redesigned and, at the same time, simplified. The switch from digitisation (downloading forms online) to digitalisation (filling out forms online) is an ongoing and often painful transition in public administrations [28]. The crisis could have fostered this transformation, by breaking down barriers and organisational inertia.

A similar reasoning may hold for the processes designed for external stakeholders, teaching in primis. All the activities of the semester moved totally online since March 2020, by generating an unprecedented and massive digital switch. Bachelor, Master and post-lauream courses were offered via Teams, which was integrated with of the respective LMSs, designed internally. The School promoted a cycle of webinars on innovative teaching methodologies, which added up to those offered centrally by the university. The possibility to take part in training sessions on teaching methods was not completely new in the School, but the level of participation by the faculty was much more consistent during the emergency, as underlined from our informants:

The online meetings were very useful for sharing experiences and finding better solutions than those I could think by myself. I was personally impressed by this aspect, as in traditional teaching I had never felt the need to share how I used to organise lessons break or lecture schedules, while in this stage I think it helped and it was a significant boost for doing better. (Delegate for Corporate Relations)

The first semester 2020/21 started by adopting an integrated approach, in which part of the class was connected online and part was face-to-face. This approach represented an additional experimentation that will make up an important wealth of experience to shape the future educational delivery mode in the School and that is likely to influence the way in which online learning is culturally conceived:

What is certain is that now our faculty have a huge toolbox. We will still have supporters and opponents of digital learning, but now we will also have a large set of practical experiences, so that our discussion will be based on that, and not only on hypotheses formulated a priori. (Academic Director) 
In this switch, the element that was perceived as the most critical was that related to the social dimension of learning [57]. The need to make decisions fast did not support the possibility to carefully redesign aspects of social interaction between the students, an aspect of learning that is instead particularly relevant in the design of courses, especially for companies and professionals.

As a final digital innovation process, the relationship with companies was transformed by a different approach to marketing and recruitment. The use of CRM gave the possibility for a larger profiling of communication and educational offer. The digital innovation products were presented to prospect consumers by combining free and paid offers, in order to provide evidence about the expertise of the School through the free webinars, attracting, at the same time, the attention to paid educational products on the same topics. The shift induced by the digital technology can be also interpreted as a cultural one, and as such, it may last in the long term with positive effects on the organisational efficiency:

You should imagine that the Sales Department suddenly ended up being without the possibility to meet customers and companies. It was tough for them. They were used to organise meetings in person, in which the relational aspect was very important. They used to spend a whole day for a single meeting. Now everything changed, everything is online, and they found out that it works as well as in the past. If this experience will make more acceptable to organise business meetings online, this will change the way in which sales are organised and will make us more efficient, by guaranteeing the same level of effectiveness. (CIO)

\subsection{The Impact of Digital Innovation on Organisational Results}

The forms of digital innovation presented above produced three main clusters of organisational impacts, which are presented together with a short description of the main initiatives in Table 3. First, many of the actions undertaken by the School had the objective to and resulted in fostering the community engagement. The informal events, the cycles of webinars, the online meetings to discuss about innovative teaching had the important result to maintain the engagement high during the crisis, reinforcing the image of the School and, possibly, its identity and reputation.

Secondly, the forms of digital innovation introduced boosted the creation of new streams of revenues for the School that was able to meet a latent demand especially by the companies and to leverage on the technological know-how already owned. The creation of short online programmes was an innovation that allowed the School to be even more present among the providers of lifelong learning, which is increasingly shifting towards short and flexible contents ready-to-use for managers and professionals [58].

Finally, the transformation undertaken by the School had an impact on the overall digital mindset, a concept that may be considered both in its "hard" (technological) and "soft"(cultural) interpretation. On the one hand, all the stakeholders had to approach new tools, applications and technologies that lowered the level technological acceptance for the future (as stated by one informant) and increased the digital skills owned, and this is a critical step along the path to full digitalisation [6]. On the other hand, the transformation of mindset is cultural, as by means of an exogenous shock, any forms of resistance were broken down, facilitating the transition and cancelling the slowing effect of the organisational inertia. 
Table 3. Description of the relationship between digital initiatives and results.

\begin{tabular}{|c|c|c|c|c|}
\hline \multirow[b]{2}{*}{$\begin{array}{l}\text { Innovative Digital } \\
\text { Initiatives }\end{array}$} & \multirow[b]{2}{*}{ Description } & \multicolumn{3}{|c|}{ Results } \\
\hline & & $\begin{array}{l}\text { Community } \\
\text { Engagement } \\
\text { (C) }\end{array}$ & $\begin{array}{l}\text { Streams of } \\
\text { Revenues } \\
\text { (T) }\end{array}$ & $\begin{array}{c}\text { Digital } \\
\text { Mindset } \\
(\mathrm{C}, \mathrm{T})\end{array}$ \\
\hline $\begin{array}{l}\text { Online Training } \\
\text { Programmes }\end{array}$ & $\begin{array}{c}\text { New training programmes available on the } \\
\text { market to foster staff training during the } \\
\text { emergency }\end{array}$ & $\bullet$ & & $\bullet$ \\
\hline A Coffee with ... & $\begin{array}{l}\text { Networking events in which a professor } \\
\text { presents him/herself to the administrative } \\
\text { staff and discusses about various topics }\end{array}$ & $\bullet$ & & \\
\hline Virtual Coffee & $\begin{array}{l}\text { Networking event to engage the staff and } \\
\text { share ideas and initiatives }\end{array}$ & $\bullet$ & & \\
\hline Nice to Tech You & $\begin{array}{l}\text { Networking event in which organisational } \\
\text { units present their activities to the staff }\end{array}$ & $\bullet$ & & \\
\hline Ciao, Let's Travel! & $\begin{array}{l}\text { Networking event to discover an } \\
\text { international country by means of movies }\end{array}$ & $\bullet$ & & \\
\hline BuonTech & Common chat for informal occasions & $\bullet$ & & \\
\hline Tech Diary & $\begin{array}{l}\text { Common group and folder to share useful } \\
\text { materials }\end{array}$ & $\bullet$ & & \\
\hline Management Skills Courses & $\begin{array}{l}\text { Short online programmes offered on the } \\
\text { digital platform }\end{array}$ & & $\bullet$ & $\bullet$ \\
\hline Online Workshops & $\begin{array}{l}\text { Online programmes offered on the digital } \\
\text { platform }\end{array}$ & & $\bullet$ & $\bullet$ \\
\hline Keep on Learning & $\begin{array}{l}\text { Dedicated webpages, materials and } \\
\text { webinars on current topics }\end{array}$ & $\bullet$ & & \\
\hline Tech Series & Cycle of webinars on current topics & $\bullet$ & & \\
\hline Teaching Talks & $\begin{array}{l}\text { Webinars offered to the staff on innovative } \\
\text { teaching methods }\end{array}$ & $\bullet$ & & • \\
\hline Process Simplification & $\begin{array}{l}\text { Partial digital redesign of administrative } \\
\text { services for guaranteeing continuity and } \\
\text { simplification }\end{array}$ & & & $\bullet$ \\
\hline $\begin{array}{l}\text { Alternative/Additional Use } \\
\text { of Marketing Channels }\end{array}$ & $\begin{array}{l}\text { Large use of CRM to foster the contacts } \\
\text { with the stakeholders }\end{array}$ & $\bullet$ & $\bullet$ & \\
\hline $\begin{array}{l}\text { Emotional and Informative } \\
\text { Videos }\end{array}$ & $\begin{array}{l}\text { Videos to provide international students } \\
\text { with informative and emotional contents }\end{array}$ & $\bullet$ & $\bullet$ & \\
\hline $\begin{array}{l}\text { Distribution of Laptops to } \\
\text { Families in Need }\end{array}$ & $\begin{array}{l}\text { Activity promoted by the faculty to collect } \\
\text { available laptops }\end{array}$ & $\bullet$ & & \\
\hline Business Games & $\begin{array}{c}\text { Business games organised for students of } \\
\text { different MBAs to foster networking at a } \\
\text { distance }\end{array}$ & • & $\bullet$ & \\
\hline
\end{tabular}

Note: letters in parenthesis refer to whether the results affected mainly the cultural (C) or technological (T) dimension. The label "Tech" substitutes the explicit name of the School. The dot indicates that the initiative contributed to the community engagement, the streams of revenues, or the digital mindset.

\section{Discussion and Concluding Remarks}

\subsection{Contributions of the Paper}

The paper contributes to show how the exogenous shock caused by the COVID-19 outbreak has been tackled to foster digital innovation in an Italian School of Management. In so doing, the study contributes to the stream of literature investigating the configuration of the digital innovation process in three innovative ways. Firstly, the paper focuses on digital innovation in response to an exogenous shock in which the crucial steps of strategy definition and strategy implementation were forcedly overlapped [10-12], thus shading new light on digital innovation in a troubled context as the one caused by the COVID-19 outbreak. To make the process of digital innovation successful, cultural elements 
mixed up with the previous experience of the HEI in the production of digital contents, by highlighting these two as organisational dimensions that are worth supporting (also in ordinary times) to be prepared for a state of emergency that is likely to be even more common in the near future [1]. Building on this, the study highlights the relevance of two conditions that can facilitate the introduction of digital innovation. The first element is the digital readiness, intended as the level of absorptive capacity of the organisation in sizing opportunities and simultaneously exploring new resources and exploiting the current practices [59]. Indeed, the previous expertise in the field of digital innovation supported the shift of the organisation towards the new paradigm. The second element is the culture of openness, favoured by the close cooperation with the external stakeholders (especially with companies) and empowerment of the academic and administrative staff, who felt the responsibility for service continuity maintaining at the same time high standards of quality [60]. In this respect, the study highlights the dynamics of digital innovation related to "soft" aspects like the organisational culture, which are commonly considered to be critical for digital transformation but limitedly explored [50].

Secondly, the paper contributes to exploring the anatomy of digital innovation in an underexplored context such as HE $[30,61]$, from which both transversal and peculiar traits emerged. Among the features that emerged as transversal to public (and private) organisations, we found the relevance of the strategic governance of digital innovation during the crisis. Indeed, the School introduced several forms of product and process digital innovation by balancing a top-down and a bottom-up approach, thus mixing a hierarchical approach to a collegial one [42], in line with the multiple cultures existing in HEIs [61]. The element of strength pointed out by many informants was the close monitoring of these actions by the governance that facilitated the coordination and favoured the organisational synergy $[62,63]$. In this respect, the results stress the relevance of the strategic orientation of digital innovation [64], especially during a crisis. The aspect that is peculiar to the HE context is the specific file rouge of such a strategic orientation. Indeed, the several initiatives all leveraged on smart learning to guarantee continuous improvement in times of crisis and to keep the community compact. Another relevant aspect was related to the contents of the learning activities delivered, which were often connected to sustainability matters in response to a need for training on these issues, especially in times of crisis. Many of the initiatives were designed to be temporarily, while they actually lasted longer than expected or evolved from their original design. The legacy of this experience will be a matter of strategic choice, in order to make them the new standards and possibly change the underlying business model of the School of Management [31,64].

Finally, by means of the several digital innovation initiatives introduced, the School fostered the sustainability discourse by supporting open and free quality education from a twofold perspective. Firstly, many activities gave the opportunity to leverage on online education for widening the accessibility and inclusivity of education, highlighting the prominent role played by HEIs in this direction, especially during a crisis as the one generated by the pandemic [3,9]. Secondly, sustainability often became the topic of the educational contents, as the economic, social and environmental aspects of the crisis were addressed in response to the stakeholder's needs for larger training on these issues during the emergency. In this perspective, the digital channel became an accelerator of the School's ability to address, deepen and train on topics related to sustainability [9].

\subsection{Practical Implications}

The practical implications of the study concern three dimensions related to technological, cultural and sustainability aspects. From a technological point of view, results can support university and other public managers in the design of similar initiatives of digital innovation. Despite being boosted by an exogenous shock, the forms of digital innovation applied in the School could be replicated in other contexts to point to the same forms of organisational results. In such an application, particular attention should be devoted to the design of the social and relational experience of the educational delivery, as that is the part that showed a certain room for improvement, especially in relation to corporate education, for which the networking and relational aspects are particularly relevant. 
From the cultural point of view, a keyword that emerged recurrently from our informants was related to the concept of trust. Given that the staff collaborated at a distance, the organisational culture was reinforced through a sense of responsibility and trust in individual contributions to the final organisational results. The digital connection relieved some of the traditional ways of interacting on the job, letting new modes emerge. In this respect, the informal climate that used to characterise the School also before the pandemic made the organisation more dynamic to tackle this switch. Moreover, the digital channel gave the possibility to create new connections and favoured synergy, thus the ability to combine the new mindset and connections with a more "traditional" way of working, in which relational aspects are predominant, creates the condition to make the most of digital innovation.

Finally, the study provides practical examples of digital initiatives to support sustainability. This has been done by means of open and free quality education offered through webinars to a wide audience, by expanding consistently the usual frequency, number of guest speakers and attendees taking part in dissemination events. This aspect offers relevant points of reflection about practical tools to increase inclusivity and accessibility of education. As a final remark, topics related to sustainability were tackled during the internal seminars as well as during the webinars, making these new initiatives a useful tool to foster sustainability in different facets.

\subsection{Limitations and Avenues for Further Research}

The limitations of the study are mainly related to its external validity, as it is based on a single case study and as such cannot be generalised straightforwardly, and to the sample of informants involved, which may be expanded. However, the affiliation of the authors to the School gave them the possibility to have a privileged point of inner observation of organisational change and dynamics. Despite being empirically related to the outbreak of the COVID-19, results may be useful for the design of digital innovation initiatives in times of "new normality". Further, it would be interesting to observe the organisation for a longer period in order to catch the long-term impact of the digital innovation initiatives generated during the COVID-19 outbreak. Thus, this may represent a future extension of our study.

Author Contributions: Conceptualization T.A., F.F. and M.S.; data collection, formal analysis and writing—original draft preparation, M.S.; validation, writing — review and editing, supervision, project administration, T.A. and F.F. All authors have read and agreed to the published version of the manuscript.

Funding: This research received no external funding.

Conflicts of Interest: The authors declare no conflict of interest.

\section{References}

1. Tesar, M. Towards a post-Covid-19 'new normality?': Physical and social distancing, the move to online and higher education. Policy Futur. Educ. 2020, 18, 556-559. [CrossRef]

2. Illanes, P.; Law, J.; Mendy, A.; Sanghvi, S.; Sarakatsannis, J. Coronavirus and the Campus: How Can US Higher Education Organize to Respond? 2020. Available online: https: //www.mckinsey.com/industries/public-and-social-sector/our-insights/coronavirus-and-the-campushow-can-us-higher-education-organize-to-respond\# (accessed on 30 November 2020).

3. Edelhauser, E.; Lupu-Dima, L. Is Romania prepared for eLearning during the COVID-19 Pandemic? Sustainability 2020, 12, 5438. [CrossRef]

4. Hodges, C.; Moore, S.; Lockee, B.; Trust, T.; Bond, A. The difference between emergency remote teaching and online learning. Educ. Rev. 2020, 27, 12.

5. Dillahunt, T.R.; Wang, B.Z.; Teasley, S. Democratizing higher education: Exploring MOOC use among those who cannot afford a formal education. Int. Rev. Res. Open Distrib. Learn. 2014, 15, 177-196. [CrossRef] 
6. Bevins, F.; Bryant, J.; Krishnan, C.; Law, J. Coronavirus: How Should US Higher Education Plan for an Uncertain Future. 2020. Available online: https://www.mckinsey.com/industries/public-and-socialsector/our-insights/coronavirus-how-should-us-higher-education-plan-for-an-uncertain-future (accessed on 30 November 2020).

7. United Nations. Transforming Our World: The 2030 Agenda for Sustainable Development. Resolution Adopted by the General Assembly on 25 September 2015 (A/70/L.1). 2015. Available online: http: //sustainabledevelopment.un.org/post2015/transformingourworld (accessed on 27 November 2020).

8. Chesbrough, H. To recover faster from Covid-19, open up: Managerial implications from an open innovation perspective. Ind. Mark. Manag. 2020, 88, 410-413. [CrossRef]

9. Abad-Segura, E.; González-Zamar, M.-D.; Infante-Moro, J.-C.; García, G.R. Sustainable management of digital transformation in higher education: Global research trends. Sustainability 2020, 12, 2107. [CrossRef]

10. Wilms, K.L.; Meske, C.; Stieglitz, S.; Decker, H.; Froehlich, L.; Jendrosch, N.; Schaulies, S.; Vogl, R.; Rudolph, D. Digital transformation in higher education-New cohorts, new requirements? In Proceedings of the 23rd Americas Conference on Information Systems (AMCIS 2017), Boston, MA, USA, 10-12 August 2017.

11. Xiao, J. Digital transformation in higher education: Critiquing the five-year development plans (2016-2020) of 75 Chinese universities. Distance Educ. 2019, 40, 515-533. [CrossRef]

12. Gafurov, I.; Safiullin, M.R.; Akhmetshin, E.; Gapsalamov, A.; Vasilev, V.L. Change of the higher education paradigm in the context of digital transformation: From resource management to access control. Int. J. High. Educ. 2020, 9, 71-85. [CrossRef]

13. Gonzalez, T.; De La Rubia, M.A.; Hincz, K.P.; Comas-Lopez, M.; Subirats, L.; Fort, S.; Sacha, G.M. Influence of COVID-19 confinement on students' performance in higher education. PLoS ONE 2020, 15, e0239490. [CrossRef]

14. Vlachopoulos, D. COVID-19: Threat or opportunity for online education? High. Learn. Res. Commun. 2020, 10, 2. [CrossRef]

15. Capano, G. Policy design and state capacity in the COVID-19 emergency in Italy: If you are not prepared for the (un)expected, you can be only what you already are. Policy Soc. 2020, 39, 326-344. [CrossRef]

16. Quattrone, F.; Borghini, A.; Emdin, M.; Nuti, S. Protecting higher education institutions from COVID-19: Insights from an Italian experience. J. Am. Coll. Health 2020, 1-2. [CrossRef] [PubMed]

17. Ginsberg, A. Measuring and modelling changes in strategy: Theoretical foundations and empirical directions. Strateg. Manag. J. 1988, 9, 559-575. [CrossRef]

18. Guth, W.D.; Ginsberg, A. Guest editors' introduction: Corporate entrepreneurship. Strateg. Manag. J. 1990, 11, 5-15.

19. Fichman, R.G.; Dos Santos, B.L.; Zheng, Z. Digital innovation as a fundamental and powerful concept in the information systems curriculum. MIS Q. 2014, 38, 329-354. [CrossRef]

20. Chan, C.M.; Teoh, S.; Yeow, A.; Pan, G. Agility in responding to disruptive digital innovation: Case study of an SME. Inf. Syst. J. 2019, 29, 436-455. [CrossRef]

21. West, D.M. E-Government and the transformation of service delivery and citizen attitudes. Public Adm. Rev. 2004, 64, 15-27. [CrossRef]

22. Coursey, D.; Norris, D.F. Models of E-government: Are they correct? An empirical assessment. Public Adm. Rev. 2008, 68, 523-536. [CrossRef]

23. Layne, K.; Lee, J. Developing fully functional E-government: A four stage model. Gov. Inf. Q. 2001, 18, 122-136. [CrossRef]

24. Henriette, E.; Feki, M.; Boughzala, I. The shape of digital transformation: A systematic literature review. In Proceedings of the 9th Mediterranean Conference on Information Systems, MCIS'15, Samos, Greece, 3-5 October 2015; pp. 431-443.

25. Wolf, M.; Semm, A.; Erfurth, C. Digital transformation in companies-challenges and success factors. In Proceedings of the International Conference on Innovations for Community Services, Wolfsburg, Germany, 24-26 June 2018; pp. 178-193.

26. OECD. Creating a Citizen-Driven Environment through Good ICT Governance-The Digital Transformation of the Public Sector: Helping Governments Respond to the Needs of Networked Societies; OECD Publishing: Paris, France, 2017.

27. Meijer, A.; Bekkers, V. A metatheory of E-government: Creating some order in a fragmented research field. Gov. Inf. Q. 2015, 32, 237-245. [CrossRef] 
28. Mergel, I.; Edelmann, N.; Haug, N. Defining digital transformation: Results from expert interviews. Gov. Inf. Q. 2019, 36, 101385. [CrossRef]

29. Nograšek, J.; Vintar, M. E-government and organisational transformation of government: Black box revisited? Gov. Inf. Q. 2014, 31, 108-118. [CrossRef]

30. OECD; EU. Supporting Entrepreneurship and Innovation in Higher Education in Italy; Organisation for Economic Co-Operation and Development (OECD): Paris, France, 2019.

31. Rof, A.; Bikfalvi, A.; Marquès, P. Digital transformation for business model innovation in higher education: Overcoming the tensions. Sustainability 2020, 12, 4980. [CrossRef]

32. PWC. The 2018 Digital University-Staying Relevant in the Digital Age. 2018. Available online: https: //www.pwc.co.uk/ (accessed on 30 November 2020).

33. Lai, K.-W. Digital technology and the culture of teaching and learning in higher education. Australas. J. Educ. Technol. 2011, 27, 1263-1275. [CrossRef]

34. Sadler, R.J. Corporate entrepreneurship in the public sector: The dance of the chameleon. Aust. J. Public Adm. 2000, 59, 25-43. [CrossRef]

35. Pohl, H.; Yarime, M. Integrating innovation system and management concepts: The development of electric and hybrid electric vehicles in Japan. Technol. Forecast. Soc. Chang. 2012, 79, 1431-1446. [CrossRef]

36. Stopford, J.M.; Baden-Fuller, C.W. Creating corporate entrepreneurship. Strateg. Manag. J. 1994, 15, $521-536$. [CrossRef]

37. Dess, G.G.; Ireland, R.D.; Zahra, S.A.; Floyd, S.W.; Janney, J.J.; Lane, P.J. Emerging issues in corporate entrepreneurship. J. Manag. 2003, 29, 351-378.

38. Turró, A.; Urbano, D.; Peris-Ortiz, M. Culture and innovation: The moderating effect of cultural values on corporate entrepreneurship. Technol. Forecast. Soc. Chang. 2014, 88, 360-369. [CrossRef]

39. Johnson, L.K. The organizational identity trap. MIT Sloan Manag. Rev. 2002, 43, 11.

40. Gal, U. Boundary Matters: The Dynamics of Boundary Objects, Information Infrastructures, and Organisational Identities. Ph.D. Thesis, Case Western Reserve University, Cleveland, OH, USA, 2008.

41. Enkel, E.; Bogers, M.; Chesbrough, H. Exploring open innovation in the digital age: A maturity model and future research directions. RED Manag. 2020, 50, 161-168. [CrossRef]

42. Chanias, S.; Myers, M.D.; Hess, T. Digital transformation strategy making in pre-digital organizations: The case of a financial services provider. J. Strat. Inf. Syst. 2019, 28, 17-33. [CrossRef]

43. James, F. How Universities can Manage the Impact of International Crises. 2020. Available online: https://www.qs.com/ (accessed on 30 November 2020).

44. Kapucu, N. Interagency communication networks during emergencies: Boundary spanners in multiagency coordination. Am. Rev. Public Adm. 2006, 36, 207-225. [CrossRef]

45. Marsen, S. Navigating crisis: The role of communication in organizational crisis. Int. J. Bus. Commun. 2020, 57, 163-175. [CrossRef]

46. Welch, E.W.; Feeney, M.K. Technology in government: How organizational culture mediates information and communication technology outcomes. Gov. Inf. Q. 2014, 31, 506-512. [CrossRef]

47. Ahn, M.J. Adoption of E-Communication applications in U.S. Municipalities: The role of political environment, bureaucratic structure, and the nature of applications. Am. Rev. Public Adm. 2011, 41, 428-452. [CrossRef]

48. Buxton, C.A.; Carlone, H.B.; Carlone, D. Boundary spanners as bridges of student and school discourses in an urban science and mathematics high school. Sch. Sci. Math. 2005, 105, 302-312. [CrossRef]

49. Singha, A.; Klarnerb, P.; Hessa, T. How do chief digital officers pursue digital transformation activities? The role of organization design parameters. Long Range Plan. 2020, 53, 101890. [CrossRef]

50. Kane, G. The technology fallacy: People are the real key to digital transformation. Res.-Technol. Manag. 2019, 62, 44-49. [CrossRef]

51. Yin, R.K. Case Study Research: Design and Methods, 4th ed.; Sage Publications: London, UK, 2009.

52. van de Ven, A.H. Engaged Scholarship: A Guide for Organizational and Social Research; Oxford University Press: Oxford, UK, 2007.

53. Walsham, G. Interactive case studies in IS research: Nature and method. Eur. J. Inf. Syst. 1995, 4, 74-81. [CrossRef]

54. Sarker, S.; Xiao, X.; Beaulieu, T. Guest editorial: Qualitative studies in information systems: A critical review and some guiding principles. MIS Q. 2013, 37, iii-xviii. 
55. Steiner, L.; Sundström, A.C.; Sammalisto, K. An analytical model for university identity and reputation strategy work. High. Educ. 2013, 65, 401-415. [CrossRef]

56. Yildiz, M. E-government research: Reviewing the literature, limitations, and ways forward. Gov. Inf. Q. 2007, 24, 646-665. [CrossRef]

57. Garrison, D.R.; Arbaugh, J. Researching the community of inquiry framework: Review, issues, and future directions. Internet High. Educ. 2007, 10, 157-172. [CrossRef]

58. Edmondson, A.; Saxberg, B. Putting Lifelong Learning on the CEO Agenda. 2017. Available online: https://www.mckinsey.com/business-functions/organization/our-insights/putting-lifelong-learningon-the-ceo-agenda (accessed on 30 November 2020).

59. Leonhardt, D.; Haffke, I.; Kranz, J.; Benlian, A. Reinventing the IT function: The role of IT agility and IT ambidexterity in supporting digital business transformation. In Proceedings of the European Conference on Information Systems, Guimarães, Portugal, 5-10 June 2017.

60. Lašáková, A.; Bajzíková, L';; Dedze, I. Barriers and drivers of innovation in higher education: Case study-based evidence across ten European universities. Int. J. Educ. Dev. 2017, 55, 69-79. [CrossRef]

61. McNay, I. From the collegial academy to corporate enterprise: The changing cultures of universities. Chang. Univ. 1995, 9, 105-115.

62. García, L.M.; Roblin, N.P. Innovation, research and professional development in higher education: Learning from our own experience. Teach. Teach. Educ. 2008, 24, 104-116. [CrossRef]

63. Martin, E.C.; Nolte, I.; Vitolo, E. The four Cs of disaster partnering: Communication, cooperation, coordination and collaboration. Disasters 2016, 40, 621-643. [CrossRef]

64. Correani, A.; De Massis, A.; Frattini, F.; Petruzzelli, A.M.; Natalicchio, A. Implementing a digital strategy: Learning from the experience of three digital transformation projects. Calif. Manag. Rev. 2020, 62, 37-56. [CrossRef]

Publisher's Note: MDPI stays neutral with regard to jurisdictional claims in published maps and institutional affiliations.

(C) 2020 by the authors. Licensee MDPI, Basel, Switzerland. This article is an open access article distributed under the terms and conditions of the Creative Commons Attribution (CC BY) license (http://creativecommons.org/licenses/by/4.0/). 